\title{
The effect of dopaminergic therapy on intraoperative microelectrode recordings for subthalamic deep brain stimulation under GA: Letter to the editor
}

\author{
Zvi Israel ${ }^{1,2}$
}

Received: 2 February 2016 / Accepted: 18 February 2016 / Published online: 1 March 2016

(C) Springer-Verlag Wien 2016

\section{Dear Editor}

I read with interest the article by Asha et al., "The effect of dopaminergic therapy on intraoperative microelectrode recordings for subthalamic deep brain stimulation under GA: can we operate on patients 'on medications'?," in your recent issue of Acta [1]. It should be pointed out to your readers that the choices of endpoints for this study are quite inappropriate.

The original reasons for discontinuing dopaminergic medication were that in awake patients this would bring about an "OFF" state in which the clinical symptoms were at their worst and so the results of intraoperative stimulation could be easily interpreted. Furthermore, patients would not have dyskinesias. If patients undergo deep brain stimulation (DBS) surgery under general anesthesia then neither of these reasons applies, and medication need not be discontinued!

It was not the development of microelectrode recording (MER) that facilitated the introduction of general anesthesia (GA) for these procedures as posited by the authors. MER was around long before GA was being used in DBS surgery. Most surgeons who have turned to using GA have done so in the realization that MER in their hands

Zvi Israel

israelz@hadassah.org.il

1 Department Neurosurgery, Hadassah University Hospital, Jerusalem, Israel

2 Functional Neurosurgery, Hadassah University Hospital, Jerusalem 91120, Israel did not improve outcomes and they could therefore rely on imaging alone.

Using MER under GA can be quite challenging. However, the most important information that will be lost is the absence or presence of beta band oscillations [2]. Beta band oscillations will also be absent in the presence of dopaminergic medication irrespective of GA. Beta oscillations are an important localizing feature within the MER data that has been associated with a better outcome [3].

There is absolutely no reason to suspect that the number of MER tracks or the geometry of the STN (length of recorded activity) will change as a result of the dopaminergic state of the patient. This is purely dependent on the targeting skill of the surgeon!

Sincerely

Zvi Israel

Associate Professor of Functional Neurosurgery

Hadassah University Hospital, Jerusalem, Israel

\section{References}

1. Asha JA, Kausear J, Krovvidi H, Shirley C, White A, Chelvarajah R, Hodson JA, Pall H, Mitchell RD (2016) The effect of dopaminergic therapy on intraoperative microelectrode recordings for subthalamic deep brain stimulation under GA: can we operate on patients 'on medications'? Acta Neurchir 158:387-393

2. Raz A, Eimerl D, Zaidel A, Bergman H, Israel Z (2010) Propofol decreases neuronal population spiking activity in the subthalamic nucleus of Parkinsonian patients. Anesth Analg 111(5):1285-1289

3. Zaidel A, Spivak A, Grieb B, Bergman H, Israel Z (2010) Subthalamic span of beta oscillations predicts deep brain stiulation efficacy for patients with Parkinson's disease. Brain 133(7):2007-2021 